\title{
NEW DEVELOPMENTS AND OPERATIONAL RESULTS IN THE USE OF FIXED SIDE-WALL INJECTORS IN THE ELECTRIC ARC FURNACES*
}

\author{
Daniele Tolazzi ${ }^{1}$ \\ Claudio Candusso ${ }^{2}$ \\ Simone Marcuzzi ${ }^{3}$
}

\begin{abstract}
Electric Arc Furnaces keep evolving into highly powerful melting units, shrinking tapto-tap times by increasing the effectiveness of the energy sources and the material fluxes used in the process. Steelmakers are targeting to increase the efficiency of their injection package in order to reduce the overall conversion costs, seeking for technologies specifically designed to promote the metallurgical reactions in a predictable and reproducible process automatically controlled at the correct timing. Many technological enhancements have focused in the gas management, improving the burner design and the penetration capacity of oxygen injectors, dedicated to decarburization and the other exothermic reactions. Instead, lower evolution efforts have been addressed to engineered solutions for managing the addition of solid materials required in slag forming, although they are playing a key role in EAF process optimization, as well. The paper describes the latest solutions designed to manage efficiently the injection of fuel, oxygen and powdered materials in several EAFs and presents the operational results achieved. Accurate control of reliable additions of coal, lime and magnesia proved crucial for the control of the slag FeO and viscosity, generating stable foamy slag and producing cleaner steel.

Keywords: Sidewall injector; Solid material; Foaming slag; Oxygen efficiency; Chemical energy; Electric arc furnace; Dust injection; Sealed door.
\end{abstract}




\section{INTRODUCTION}

\subsection{CHEMICAL ENERGY MANAGEMENT AS AN INTEGRATED PROCESS IN THE ELECTRIC ARC FURNACE}

Fast metallic charge melting requires appropriate capability to manage the chemical energy in the most efficient way, according to the rapidly changing conditions within the furnace environment [1]. The melting power and the metallurgical processes can be managed only by specialized equipment and careful process control to attain high productivity performances at minimum energy consumption [5]. Sinergy between electrical arc power schedule and correct chemical action can lead to consistent savings in consumptions and time. Melting scrap in an Electric Arc Furnace require a number of process functions to be fulfilled:

- Heat and melt down the scrap pile;

- Oxidize silicon, phosphorus, chromium and carbon;

- Correct the slag chemistry and control the iron oxide production;

- Foam the slag;

- Limit the carbon monoxide output and control the combustion within the furnace;

- Protect the refractory lining from corrosive wearing.

Steelmakers can profit from the appropriate management of all these actions only if their furnace is equipped with an efficient and reliable chemical package [6]. The most important figures required to such equipment are:

- specialized mechanical design completed by a dedicated assembly on the furnace lay-out;

- fast and precise regulation according to the melting program and the process control;

- flexibility, reliability and consistency;

- Equipment stiffness and maintainability.

Those figures can be attained only by a comprehensive integration of the EAF process functions with the design of the equipment.

\subsection{A COMPLETE CHEMICAL PACKAGE FOR THE MODERN EAF}

Most of the fixed wall systems available today on the market already provide effective oxygen injection for decarburization and oxidation reactions. The efficient injection of solids, such as fuel carbon and foaming carbon, or lime and dolomite for slag conditioning, stays still a challenge rarely solved with effective engineered solutions.

MORE, in the past years, has always considered the injection improvement in the EAF as a whole process, where oxygen injection is intimately associated to solids' injection. Such integration is driving the design concept for a complete chemical package to equip the modern EAF. Smart and efficient use of energy and material resources are the corner stone for the improvements in conversion cost, productivity and metallurgical quality of the final product.

MORE chemical energy technology includes specialized fixed wall injectors, each dedicated to specific functions crucial for the process operations. These functions are regulated by dedicated valve trains, coal and lime dispensers, controlled by reliable 
automation systems, embedding a valuable know-how, matured in several years of experience and process knowledge.

The on-board equipment of the EAF shell comprises four different tools (Fig. 1):

1. M-ONE: an all-in-one injector integrating supersonic oxygen lancing capacity and coal delivery intimately coordinated to generate and promote slag foaming and precisely control redox reaction mechanism at the slag-metal interface;

2. OXYGENJET: dedicated to supersonic oxygen for lancing. As per M-ONE, this injector delivers a highly coherent supersonic stream of oxygen that is able to penetrate into the steel bath to complete the oxidizing reactions. It is mostly used as a supplementary injection point, especially to clean the scrap and the skulls at the sump area, in order to assure EBT free-opening.

3. LIMEJET: a tool specifically designed for the injection of the fluxes into the slag. Typical injected solids are lime and/or dololime, added to modify the slag chemistry and foam it.

4. HI_JET: a supersonic coaxial injector dedicated to introduce powdered fines at very high speed under the slag-metal interface. The annular supersonic gas stream confines the powdered particles by shrouding and transfers the momentum accelerating them along the axis.

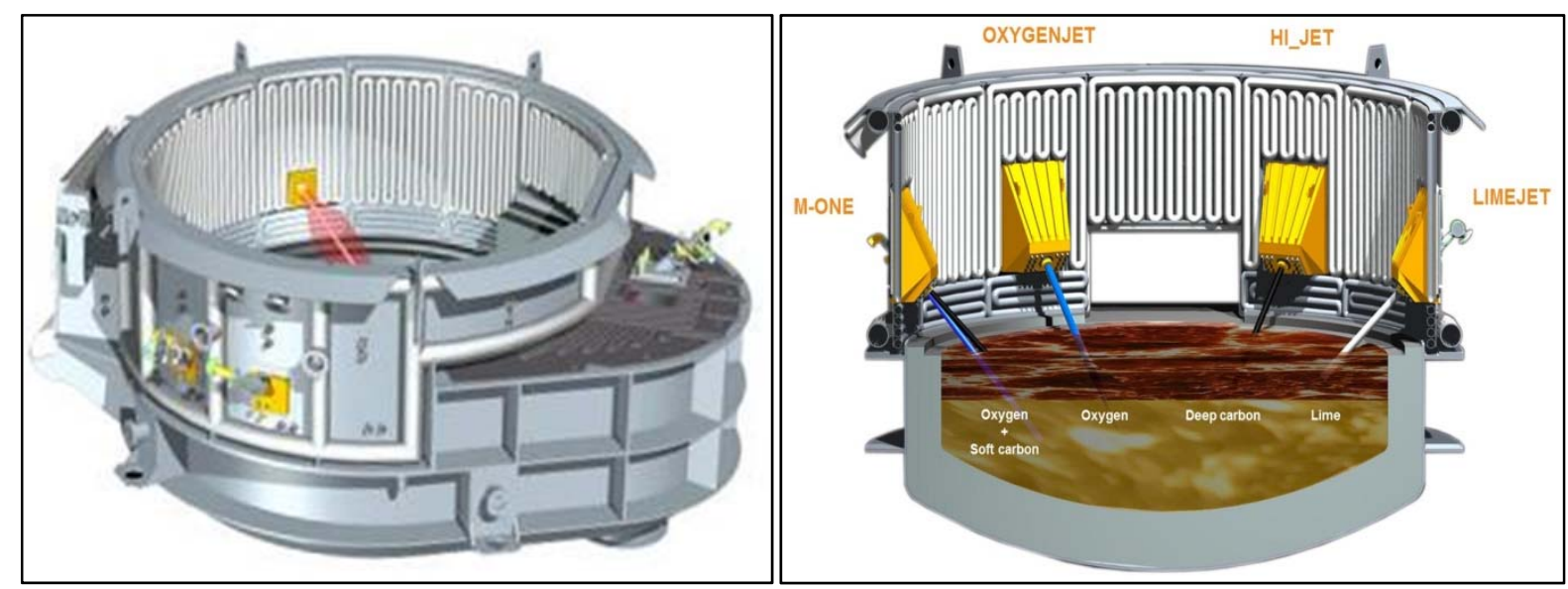

Fig. 1 - COMPLETE CHEMICAL PACKAGE FOR THE MODERN EAF

All the above-mentioned tools are equipped with high efficiency oxy-fuel burners for heating the scrap and assisting the charge meltdown. Energy dissipation, gas leaks, backfire, accumulation of materials at the walls, steel splashing and oxygen reflection are the most common counter backs causing bad performances, delayed and uneven melting and inevitably leading to equipment damage. All MORE injectors are equipped with Mixed Swirling Flame burner technology to fulfil all these requirements. Oxygen and carbon injection in the metal-slag system are driving a synergic double effect: oxidation of carbon and metallic elements is producing chemical energy in the liquid pool, while iron oxide reduction is generating a carbon monoxide boil diffused over the entire liquid surface within the slag. The gas foams the slag and mixes it, in a turbulent process of thermal homogenization, which becomes the vehicle of heat transfer.

In order to reach the highest kinetics, it is very important to control the rate of reaction between the metal bath and the slag layer. Adoption of different injection tools with dedicated accurate flow control equipment, enables the simultaneous production of 
exothermic chemical reactions in the liquid bath and the retention of the heat power at the slag/steel interface by the early generation of excellent foaming slag.

The capacity to modulate the reactions between the metal bath and the slag permits to control the oxygen activity in the steel in a narrower range, with relevant savings in the alloy consumption and yield. Compensation of structural carbon introduced via the metallic charge mix is possible within a normal range of operation even in the case of $\mathrm{DRI} / \mathrm{HBI}$ use, eliminating the need for charging coal via the roof or the scrap bucket, whose environmental impact is usually very severe.

Thanks to their peculiar design, the injectors deliver their high kinetic momentum into the liquid steel, producing a heavy bath stirring, removing temperature and chemistry stratification.

The regulation of the slag chemistry and the inherent viscosity and melting temperature properties are the key point. The addition of the slag modifiers in the proper feed rate and timing by specific engineered equipment is therefore playing a complementary key role $[7,5]$.

LIMEJET and the associated pneumatic conveying technology enable to perform the flux additions close to the slag from the sidewall, increasing the added materials recovery rate and reaction promptness. As a side effect, in addition to the metallurgical role, the orientation of the lime jet stream to the hot spots permits to protect the lining and the shell from open arc radiation extending the equipment lifetime.

Finally, the capacity to inject fluxes efficiently even during flat bath operation permits to control the slag basicity throughout the entire heat. During superheating, in fact, temperature increases and the concentration of low melting point species, mainly iron oxide, causes a natural de-foaming effect [8]. The rapid response of the sidewall injection permits dosing fluxes up to the heat endpoint, keeping the slag foaming covering the arcs until tapping, preventing open arc radiation and nitrogen pickup.

\subsection{MIXED SWIRLED FLAME BURNER TECHNOLOGY}

The burner mode operation is very important for each wall fixed tool on the scrap pile. At first, the metallic charge requires to be heated evenly on the periphery. Because the electric arc power is very high, the charge is rapidly molten in the furnace center, while it stays cool on the periphery. This fact will produce, in turn, scrap cave-ins, affecting the arc power stability and electrode consumption. Moreover, uneven melting - especially in weakly powered AC furnaces, produces a lot of scrap sticking on the cold spots. In order to overcome its undesirable effects, it is required to extend long arc practice in the melting phases in which the water-cooled walls are unprotected.

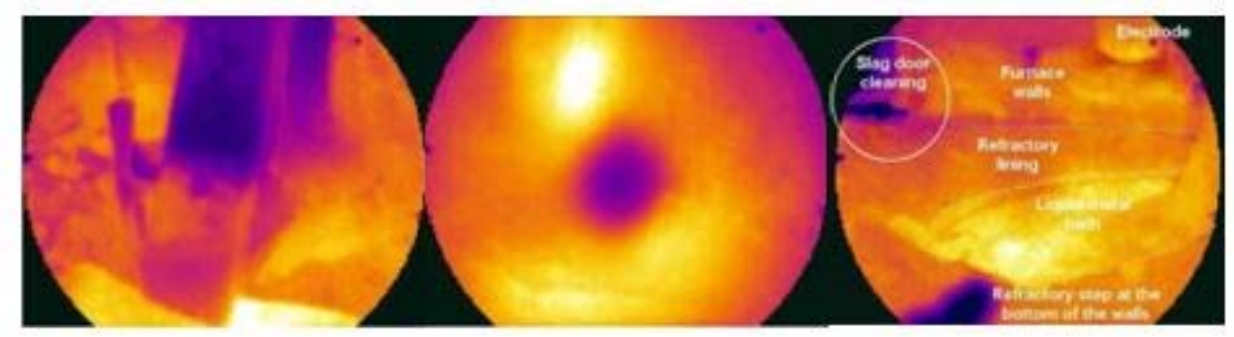

Fig. 2 - Endoscopic thermal image through a sidewall injector [16, 19] 
The thermal heat input proceeds from the flame to the scrap material, with the purpose to rapidly heat its surface and melt it down efficiently, preparing the subsequent phase for injection (Fig. 2).Requirements for an efficient flame heating are: produce the highest radiative and hottest flame, spread the heat power on a wide area, avoid separation between fuel-rich and oxygen-rich streams. The mixed swirled burner technology was developed to properly mix in the correct ratio the fuel gas and the oxygen, in order to obtain a well-stirred gas mix ready to ignite few millimeters after the injector tip.

The benefits obtained are:

- $100 \%$ fuel heat potential exploited in a larger and shorter flame volume;

- eliminate loss of fuel, uncontrolled combustion or endothermic reactions with skull formation;

- avoid free oxygen streams that are producing liquid slag and causing localized refractory erosion;

- reduce the risk of backfiring and eliminate escape of flames from the shell, due to gas out leakage;

- tip and nozzles self-cleaning capacity.

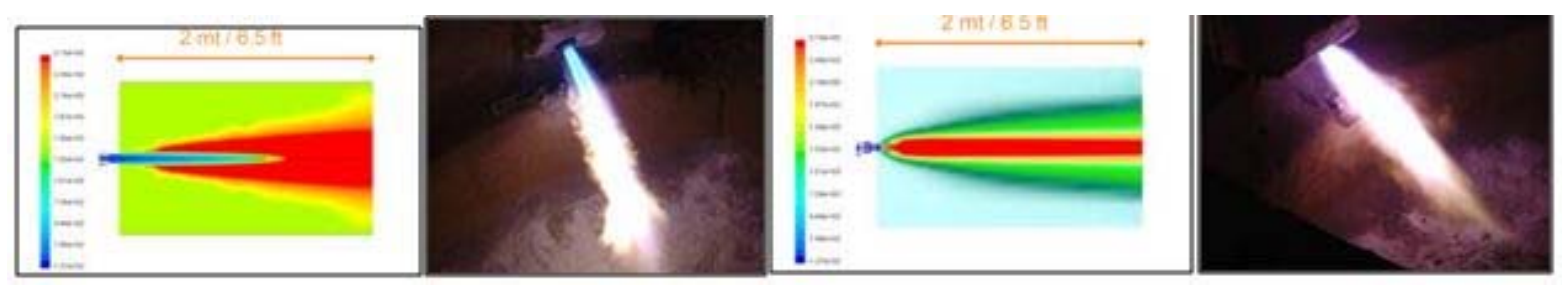

Fig. 3 - Burner comparison: conventional axial diffusion flame (left), mixed swirled flame (right)

A specific research project has been set up to improve combustion and heat transfer efficiency to the scrap surface $[17,18]$. The peculiar burner tip design dramatically improves the mixing of reactants and avoids the generation of a cold flame that is very evident from the temperature field comparison of a mixed swirled oxy-natural gas/LPG flame to a conventional axial diffusion flame (Fig. 3).

\subsection{THE PROCESS OPTIMIZATION OF THE OXYGEN LANCING}

Nowadays, the availability of very accurate computational fluid-dynamics is a very powerful modeling tool to support engineers in the conception and selection of the best design solutions [2,3,4]. MORE nozzle for oxygen injection was generated thanks to this advanced approach. It is capable of generating a highly coherent supersonic stream of oxygen that conserves the momentum for a large traveling distance up to the steel bath. MORE has developed a proprietary design code based on the "Method of Characteristics" modified with a "Boundary Layer Correction" to take into account of non-ideal friction viscous losses near to the walls. Nozzles designed according to this code run shock-free, producing a free jet structure perfectly adapted to the discharge ambient conditions. The benefits related to the nozzle design are further enhanced by the natural shrouding generated by CO post combustion within the EAF (where carbon monoxide ranges between $20 \%$ to $40 \%$ 
during the injection of carbon and oxygen) and allows to retain oxygen supersonic velocity up to a distance of roughly 2 meters (Fig. 4).

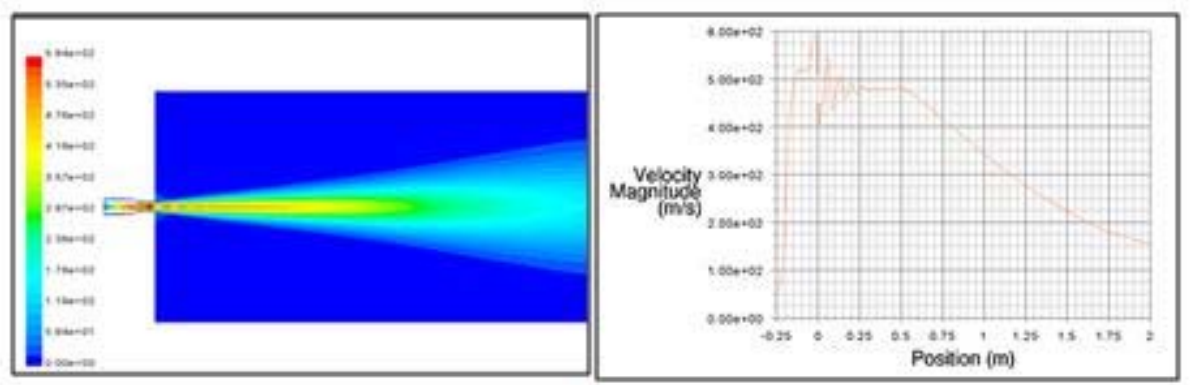

a

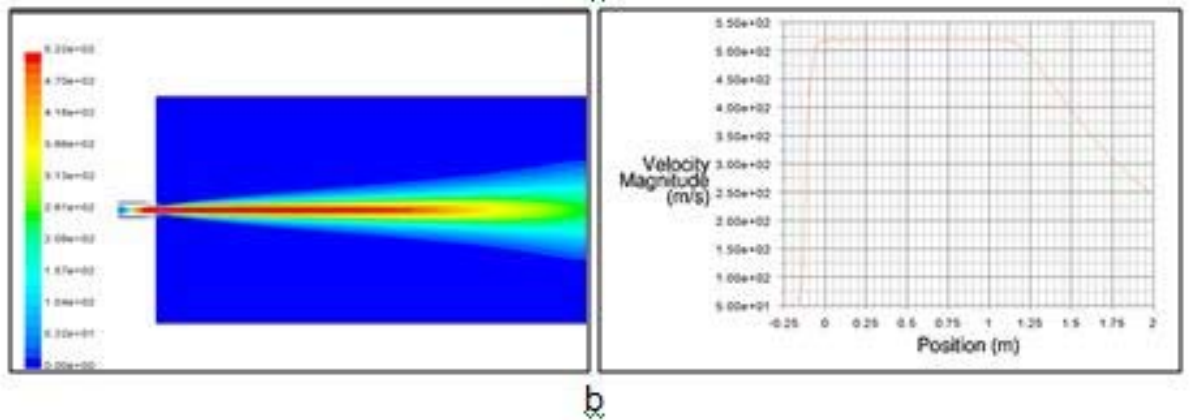

Fig. 4 - Oxygen jet structure: a. conventional; b. optimized design

\subsection{CONVENTIONAL SOLID MATERIAL SOFT- INJECTION AND ITS LIMITATIONS}

Coal injection from the sidewalls has always been performed mainly by simple pipes, installed through refractory walls or through the water cooled panels (eventually protected in water cooled jackets). These tools inject the carbon particles at a velocity in the range of 25 to $65 \mathrm{~m} / \mathrm{s}$. As shown by extensive gas flow modeling (Fig. 5 ) the dispersion of fine particles is very fast in this range of velocity.

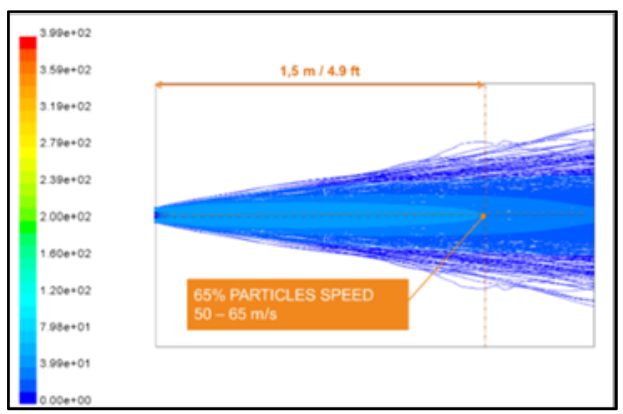

Fig. 5 - SOLID PARTICLES IN CONVENTIONAL SOFT INJECTION

The effects of fine particle dispersion in the furnace volume is a low material yield and above all a loss of reaction control in the slag. It is a common observation, in fact, that dispersed particles are sticking in the pipe neighborhoods are causing skull buildup, due to endothermic reactions promoted by carbon. The build-up is causing clogging or powdered material deflection impairing the important reactions required for slag conditioning. 
M-ONE is the most advanced fixed wall injector that was born as a synthesis of all the required functions analyzed in the previous chapters. It is a single unit integrating three functions:

- Mixed swirled flame burner;

- High efficiency supersonic coherent oxygen lancing

- High momentum powdered solid injector

The all-in-one design was initially developed with the target to reduce the number of tools installed in the furnace shell, in order to ease the assembly work, to reduce the capital investment and to improve the reliability of equipment. Sooner, it was clear that integrating oxygen lancing and coal injection in a single unit was leading to a number of advantages coming from the synergy of the three functions. The powerful mixed swirled flame, spreading on a larger diameter is improving the burner efficiency, involving larger portions of scrap and having a reliable self-cleaning effect against tip clogging, without the need of any low oxy-fuel flame to prevent the slag sticking and skull formation.

Oxygen lancing is therefore more effective, adding to the advanced design and control of the De Laval nozzle rapid scrap meltdown and early access to the melt. Coal is reacting immediately with the iron oxide produced by oxygen, controlling the refractory corrosive potential of the liquid slag initially produced during scrap melting. In the past, the distance between the oxygen lancing and the coal injection required time to complete the passivation redox reactions.

Engineers took advantage from the vicinity between the oxygen and the coal jets to accelerate the solids' particles by the faster oxygen gas stream. Extensive CFD parametric modeling was performed in order to maximizing the solid particles acceleration by entrainment effect without losing the supersonic oxygen free-jet structure.
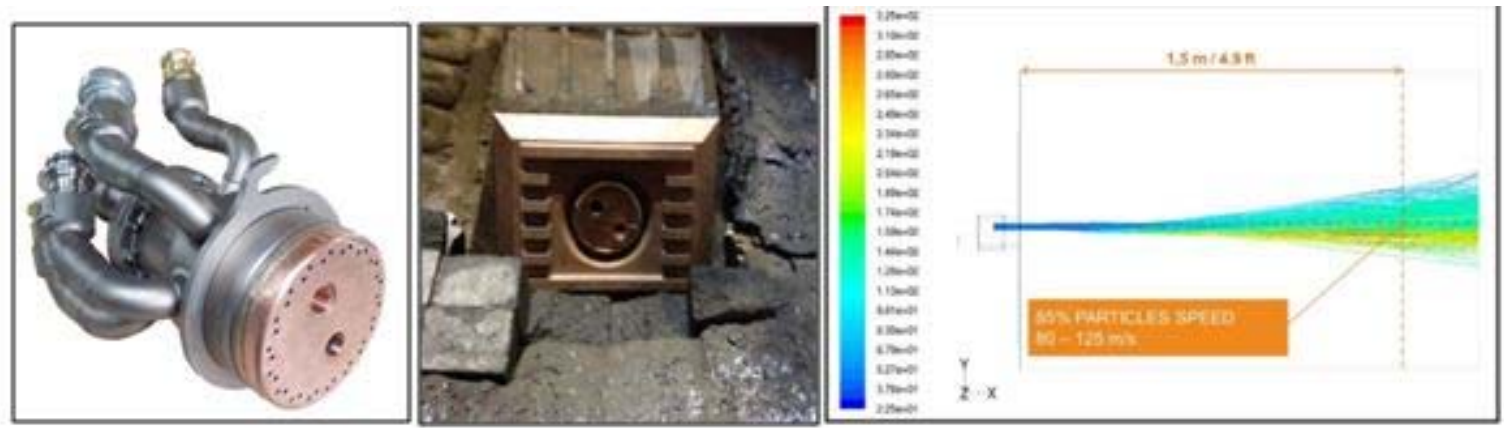

Fig. 6 - M-ONE INJECTOR

The injector body was developed to obtain a compact arrangement with the target of a lightweight to allow a single person manual handling, not requiring any special equipment for lifting (Fig. 6).

The M-ONE injector is fully integrated with the flow regulation equipment: the valve trains for fuel and oxygen regulation and the coal pneumatic dispenser. The full package makes the application extremely versatile to adapt to any charge mix 
keeping the effectiveness performances at the top values. The design conception of the M-ONE injector is making it the perfect tool for foaming slag control.

The features of the M-ONE design described above have been proven in practice by the excellent results achieved in several plants (table 1), where the original setup was simply replaced by the new technological package.

\begin{tabular}{|c|c|c|c|c|c|c|c|c|}
\hline & \multicolumn{2}{|c|}{\begin{tabular}{|c|} 
plant A \\
80 ton, $10 \%$ scrap $90 \%$ cold DRI \\
3x M-ONE [1800 Nm3 $3 / \mathrm{h}, 45 \mathrm{~kg} / \mathrm{min}]$
\end{tabular}} & \multicolumn{2}{|c|}{$\begin{array}{c}\text { plant B } \\
120 \text { ton, } 100 \% \text { hot DRI } \\
3 \times \text { M-ONE }[2300 \mathrm{Nm} 3 / \mathrm{h}, 40 \mathrm{~kg} / \mathrm{min}]\end{array}$} & \multicolumn{2}{|c|}{$\begin{array}{c}\text { plant C } \\
110 \text { ton, 82\% scrap } 18 \% \text { DRI } \\
3 \times \text { M-ONE [1500 Nm3 } / \mathrm{h}, 30 \mathrm{~kg} / \mathrm{min}]\end{array}$} & \multicolumn{2}{|c|}{$\begin{array}{c}\text { plant D } \\
85 \text { ton, } 100 \% \text { scrap } \\
\text { 3x M-ONE [2500 Nm3 } / \mathrm{h}, 30 \mathrm{~kg} / \mathrm{min}]\end{array}$} \\
\hline & before & after & \begin{tabular}{|l} 
before \\
\end{tabular} & after & before & after & before & after \\
\hline Power On [min] & 37,6 & 36 & 44 & 39 & 33 & 32 & 34 & 33 \\
\hline Electrical energy $[\mathrm{kWh} / \mathrm{t}]$ & 521 & 495 & 550 & 503 & 445 & 415 & 393 & 378 \\
\hline Oxygen $[\mathrm{Nm} 3 / \mathrm{t}]$ & 31,3 & 38,8 & 28 & 36 & 31,7 & 33,3 & 32,5 & 27,2 \\
\hline natural gas $[\mathrm{Nm} 3 / \mathrm{t}]$ & 2,6 & 2,5 & 2,9 & 2,6 & 3,2 & 3,2 & 7 & 5,8 \\
\hline carbon $[\mathrm{Kg} / \mathrm{t}]$ & 15 & 23 & 9,5 & 15,5 & 34 & 30,6 & 20,6 & 20,5 \\
\hline Yield [\%] & 89,2 & 90 & 84 & 84 & 92,4 & 94 & 92 & 92 \\
\hline
\end{tabular}

Table 1 - M-ONE OPERATIONAL RESULTS

\subsection{THE COPPER BULGED BLOCK: A TECHNOLOGICAL UNIT, NOT SIMPLY A TILE BOX}

Fixed wall injectors provide a lot of benefits compared to movable lances, but they have to cope in any case with the higher jet traveling distance from the wall to the bath. The reduction of jet's traveling distance to the melt is of major importance for the injectors' efficiency. Moreover, the space between the injector tip and the bath is initially full of scrap and sometimes skulls and bulky aggregates with solid slag settle over the refractory walls.
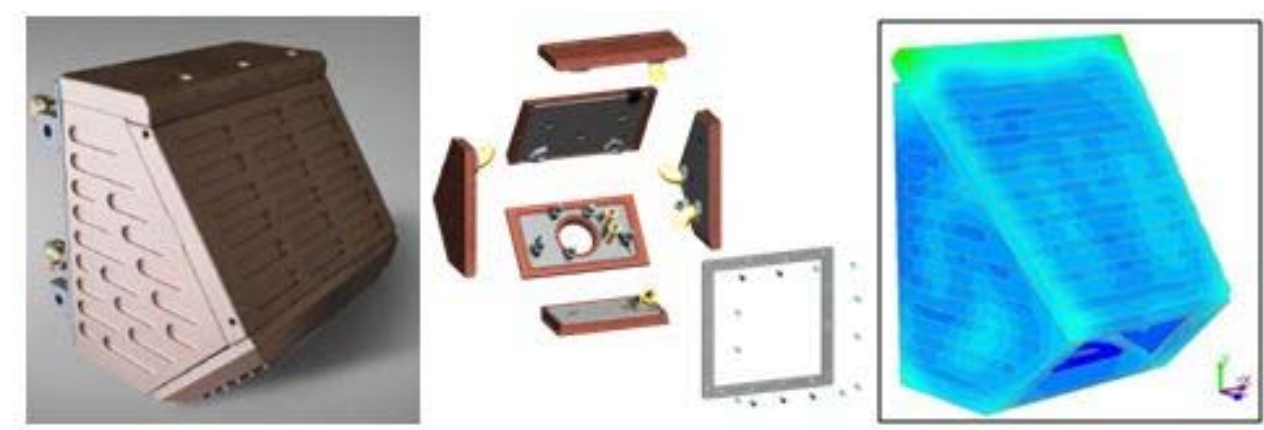

Fig. 7 -BULGED BLOCK ASSEMBLY AND CFD MODELING

The bulged block (Fig. 7) was specifically conceived to protrude inside the furnace in order to shorten the travelling distance from the injector tip to the melt. Its sturdy design holds the heavy impulsive loads transmitted by the scrap during bucket loading. A lot of attention has been placed in optimizing the water cooling distribution and heat extraction efficiency. The thermo-mechanical design was optimized to sustain the highest thermal stresses and to avoid components' deterioration related to cyclic thermal fatigue phenomena.

Due to very high thermal radiation loads, we selected copper alloy material for the application, required for its best compromise between strength and thermal conductivity. Initially castings were adopted. Soon several restrictions coming from foundry practice shaded constraints in the design and manufacturing effectiveness of 
the parts. Moreover, prototyping and improvement in the components' design was very expensive, taking long time before being available for the production stage.

Finally, total quality control, which is one of the cornerstones of the Company's policy, was not $100 \%$ in our hands: non-destructive testing to confirm the absence of casting defects was practically impossible. Along the years, despite longer supply lead times, we saw a progressive degradation in the copper alloy quality, reducing the components' lifetime and creating higher safety risks for the operations.

Our engineers performed a careful failure mode analysis of the supplied components. It highlighted that most of the failures were happening in the front part of the bulged block, close to the injectors' tip. The rest of the component, regardless it was continuously hit by the scrap, showed only the effects of regular wearing and was really long lasting. Designers developed a version with the front plate manufactured as a separated part. Therefore, in case of leak, it was possible to replace only the front plate, saving the copper block. Post-mortem analysis was showing that almost all the failures were coming from two factors:

- A casting defect in the copper alloy part;

- Injectors' backfiring due to flame or free oxygen impingement on a heavy piece of scrap.

Therefore, we started manufacturing the front plate from a copper alloy forged raw part, milled to obtain the ideal channeling for water-cooling. We also embedded in the front copper plate the FLASH STOP system, real time diagnostics dedicated to detect any risk of backfire and to prevent any risk of damage. Whenever FLASHSTOP is generating an alarm, the flame or oxygen injection immediately stops (Fig. 8) or reduces to a safety low regime until the warning occurrence disappears.

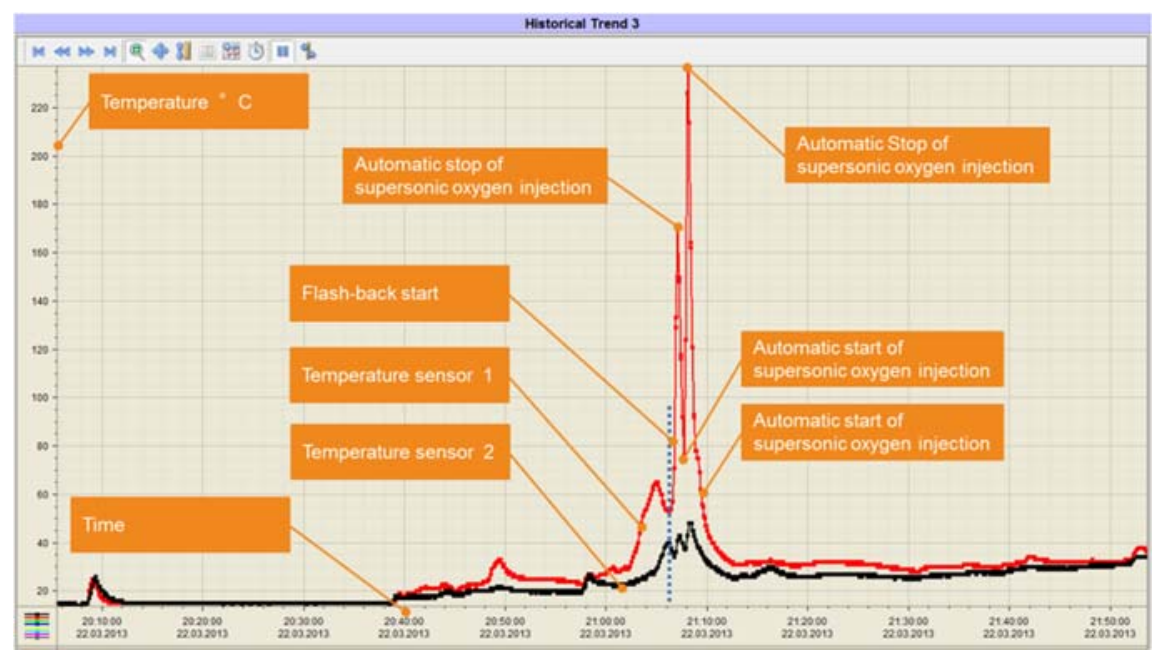

Fig. 8 - FLASH STOP DETECTION SEQUENCE

The immediate advantage is the protection of the bulged block and injector from any risk of damage. At the same time, the frequent occurrence of backfire warnings is highlighting to the technologist the urgency to check the charge preparation or to reconsider the applied set points to the unit in the melting profiles. The results initially obtained with the new front plate design were really outstanding. At the same time, all the previous design and manufacturing constraints and limitations disappeared. We immediately decided to extend the concept to all the components forming the bulged 
block and equipped our workshop to control all the manufacturing operations in house. The advantages of the actual bulged block supplied by MORE are:

- Optimized thermo-mechanical design with low water flow consumption;

- Complete manufacturing cycle under total quality control, from raw material (100\% free from defects, IACS conductivity proven, copper alloy certified) to final assembly (dimensional, welding procedures, seam testing, water pressure proof and water flow test);

- Very short lead time and just in time production;

- Flexibility ensured by: CAE CAD CAM integration.

MORE's copper bulged blocks guarantee a superior duration and permit to optimize the assembly of the injectors on the furnace shell, shortening the distance to the bath and maintaining the proper orientation and inclination of the installed equipment along time. EAF productivity improves thanks to increased furnace availability: several experiences showed that the occurrence of delays previously caused by failing equipment have reduced to zero after the installation of MORE's copper bulged blocks. As a consequence, reduced maintenance efforts for cleaning or repairing equipment are required, too.

\subsection{PNEUMATIC LIME INJECTION: THE SLAG FORMER TOOL}

LIMEJET is a tool injecting lime / dololime at a velocity of 60 to $80 \mathrm{~m} / \mathrm{s}$, sufficient to reliably penetrate the slag surface and deposit and disperse even the finer particles of flux inside the bulk (Fig. 9).

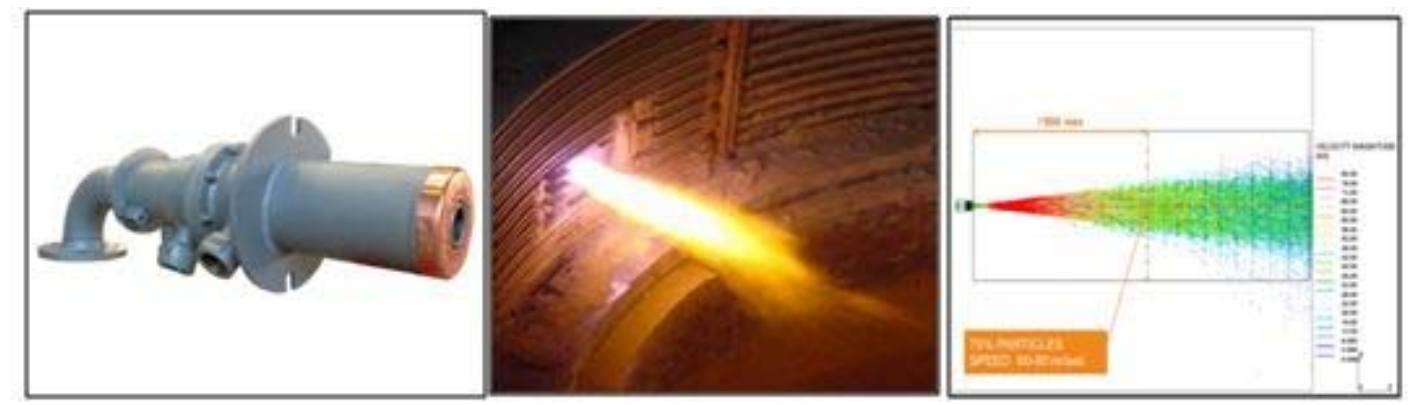

Fig. 9 -LIMEJET SIDEWALL INJECTOR

The LIMEJET injector provides for the control of the slag V-ratio and temperature. These functions are especially valuable during the last part of the heat, during bath superheating when slag tends to de-foam as a consequence of $\mathrm{FeO}$ concentration $[10 ., 11,12,13]$.

Sidewall injection is close to the slag. The shorter jet travelling path limits fine losses to the off gas system. Consumptions savings and less dust load to the baghouse are direct benefits of the high material recovery.

The injector is fitted with a wear-resistant pipe, selected to withstand the material abrasion effect.

The limejet is equipped with a powerful mixed swirled flame burner mode. It operates for heating and melting the scrap pile in front of the injector and prevents the "cold balloon" formation at the wall that is frequently suffered in conventional installations that are therefore prone to clogging. 


\subsection{HI_JET FOR ENHANCING THE INHECTION EFFICIENCY OF DUSTY} POWDERED SOLIDS

This unique injector, the concept of which is adopted from an original BOC Gases patent, incorporates the latest developments of fixed injection [11]. The peculiarity of this tool is the injection of the carbon fines embedded into an annular supersonic oxygen stream. Due to the high velocity oxygen stream, the carbon particles exchange momentum with the oxygen and increase their speed up to $400 \mathrm{~m} / \mathrm{s}$ (Fig. 10) for a distance of about $2000 \mathrm{~mm}$.

The powdered material stream (particles' velocity reaches about ten times the values of conventional injection) pierces the slag layer and delivers the solids directly into the molten steel. Short traveling time limits any reaction with the slag.

When applied to inject coal material, particles react only with bath-dissolved oxygen. This method allows for direct control of the oxygen activity in the steel.
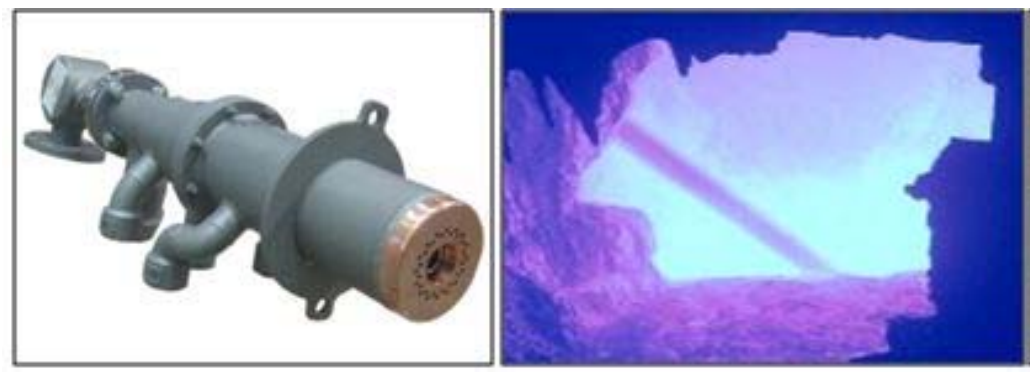

Fig. 10 - HIJET

Thanks to the high velocity and momentum transferred to dusty particles, the recovery rate of loaded solids is very high compared to conventional methods. Some applications are now under extensive testing in order to use HiJET for injecting dusty solids with a useful chemistry (containing high metallic ratio) into the EAF process instead of disposing them.

\section{CONCLUSION}

The management of the thermal energy and the complex chemical reactions taking place in the electric arc furnace process require a well-integrated and complete technological package. Fixed side-wall equipment dramatically improved the furnace availability, eliminating the frequent delays related to traditional equipment failures. Process control automation can be applied eliminating manipulation. Process run steady, repeatable and predictable, leveling the performances of different crews.

While most of the previous work focused on the optimization of supersonic oxygen injection, design of the De Laval nozzles and optimization of the stream inclination to limit splashing effects, we focused the research activity for new tools, concentrating also on the efficiency of powdered solids' injection. M-ONE injector, precisely fitted in MORE copper bulged block, is the proof that a smart integration between a high thermal power burner, and efficient coherent supersonic oxygen jet and a dedicated coal stream can create a synergy overwhelming the simple juxtaposition into a new superior tool.

When considering dusty powdered materials, that are very difficult to efficiently load in the process, dedicated specialized equipment like the HI-JET can be applied. The high momentum produced by the HI-JET injector is transferred to the powdered solid 
matter. Grains, confined by the concentric annular supersonic jet, are accelerated to a very high speed and focused inside the melt. Different interesting applications of high potentiality have been tested, from aluminum in high-grade stainless steel production to wastes recovered from ferroalloy storage cleaning, proving as effective for the high recovery rate. The main application of the Hi-Jet still stays in delivering carbon deep into the melt in order to reduce the oxygen activity and to recover iron units, still maintaining a good rate of carbon boil reaction.

Slag management in steel production is as important as the bath management. LIMEJET injectors efficiently add fluxes to the slag, acting close to the bath. They are reducing the dust losses to the fumes plant experienced when loading the slag builders from the roof. Pneumatic conveyors have fast response, enabling for accurate corrections during the superheat period, as well as efficiently adding the bulk quantities required in short times.

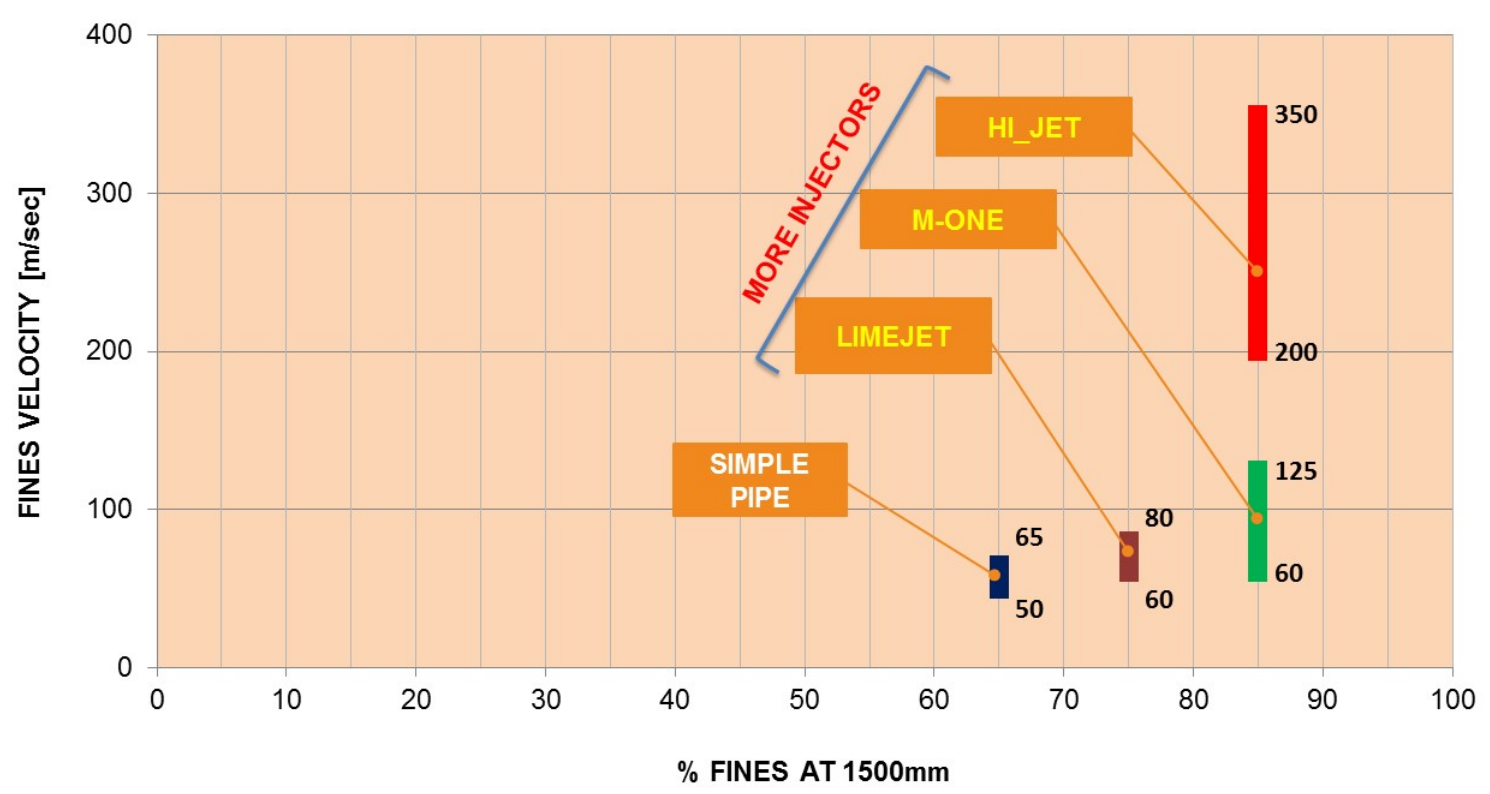

Fig. 11 - SOLIDS' INJECTION EFFICIENCY A VELOCITY COMPARISON

OXYGENJET injector is complementing the complete package, dedicated to supplement chemical energy locally in cold spots, especially in the sump area. The complete set of specialized injectors fitted into the dedicated copper bulged blocks permit to control the thermal and chemical energy efficiently in the EAF process by automatic process scheduler, according to different injection profiles specifically adapted for different steel grades and charge mixes. The furnace personnel is completely free from manual intervention.

Sealed slag door operation reduces to a minimum extent the infiltrated air, limiting the electrodes' consumption, too. In addition, the dedusting system can run more efficiently. Charge carbon use, usually producing large flames and overheating of the FTP during bucket loading, should be limited. Efficient coal injection permits a better control in the equilibrium of carbon and oxygen, improving the charge yield. Direct benefits are: higher and steady productivity, decrease in electric energy, higher materials recovery and a better yield. 


\section{REFERENCES}

1 M. HAISSIG, Enhancement of EAF Performance by Injection Technology - The Environment Within, Symposium on Iron and Steelmaking, McMaster University, Hamilton, Ontario, Canada, May 24-26, 1994

2 M. ALAM, J. NASER, G. BROOKS, A. FONTANA, Computational Fluid Dynamics modeling of supersonic coherent jets for EAF Steelmaking process, Metallurgical and Materials Transaction B, dec 2010, vol 41 B, pp. 1354

3 F. MEMOLI, C. MAPELLI, P. RAVANELLI, M. CORBELLA, Evaluation of the Energy Developed by a Multipoint Side-wall Burner-Injection System during the Refining Period in a EAF, ISIJ International, Vol. 44 No. 9 (2004),pp. 1511-1516

4 F. MEMOLI, C. MAPELLI, P. RAVANELLI, M. CORBELLA, Simulation of Oxygen Penetration and Decarburisation in EAF Using Supersonic Injection System, ISIJ International, Vol. 44 No. 8 (2004), pp. 1342-1349

5 OPFERMANN, D. RIEDINGER, Energy Efficiency of Electric Arc Furnace, AISTech Conference Proceedings, 2008, pp.

6 OPFERMANN, D. RIEDINGER, S. BAUMGARTNER, A. GROSSE, Improvement of Energy Efficiency in EAF Steelmaking, Millennium Steel (2009), pp 65-72

7 S. BARELLA, A. GUTTADAURIA, C. MAPELLI, D. MOMBELLI, Critical evaluation of role of viscosity and gas flowrate on slag foaming, IRONMAKING \& STEELMAKING VOL 39(6) (2012), pp 463-469

8 MAPELLI, D. MOMBELLI, S. BARELLA, P. TREZZI, G. FERRARI, C. CAGNI, Experimental trials and theoretical background about foaming, slag refractory interaction and feasibility of crude magnesium carbonate injection as foaming agent and its use for EAF refractory protection, La Metallurgia Italiana issue 5, 2014, pp 29-36

9 M. SEDLMEIER, D. SCHMIDT, K. VAMVAKAS, M. IACUZZI, Innovative EAF burner technology and solid material injection, STAHL UND EISEN 130/01 Verlag Stahleisen Mbh (2010), pp 63-81.

10 MCGILL, M. IACUZZI, A. BEASLEY, Applications and Operating Results of Pneumatic Lime/ Dololime Injection Technology in Severstal (SDI) Columbus EAFs, AISTech 2015 Steel Conference, Cleveland, USA

11 L. WOLFE, J. P. MASSIN, T. HUNTURK, W. RIPAMONTI, Lime Injection Technology A Viable Tool For The Electric Arc Furnace, technical paper:

http://www.carmeusena.com/sites/default/files/brochures/steel/tp-lime-inj-eaf-2008.pdf

12 WOLFE, J. KORN, Overview Of Lime Injection In The Electric Arc Furnace, technical paper: http://www.carmeusena.com/sites/default/files/brochures/steel/tp-lime-inj-eaf2007.pdf

13 R. McClanahan, L. Kibler, L. Wolfe, A. C. Dyar, J. M. Compton, Comparative Analysis of Dolomitic Lime and Chinese Magnesite Practices in Electric Arc Furnace Steelmaking Slags, technical paper: http://www.carmeusena.com/sites/default/files/brochures/steel/tp-nsbhp-20paper-aise202003.pdf

14 Pujadas, J. McCauley, M. lacuzzi , Eaf Energy Optimization At Nucor Yamato Steel, Iron and Steel Technology 2004

15 M. Liukkonen, K. Penttilä, P. Koukkari, A compilation of slag foaming phenomenon research, Theoretical studies, industrial experiments and modelling, VTT Technical Research Centre of Finland 2012, http://www.vtt.fi/inf/pdf/technology/2012/T63.pdf

16 P. NYSSEN, C. MATHY, L. BELLAVIA, M. WEBER, J. C. BAUMERT M. S. MILLMAN G. ANTONELLI, Control by camera of the EAF operations in airtight conditions, Research Fund for Coal and Steel Contract No RFSR-CT-2004-00008, 2004-2007

17 A. FRASSOLDATI, A. CUOCI, T. FARAVELLI, E. RANZI, C. CANDUSSO, D. TOLAZZI, Simplified kinetic schemes for oxy-fuel combustion, 1st International Conference on Sustainable Fossil Fuels for Future Energy - S4FE, 2009 
18 A. Cuoci, A. Frassoldati, T. Faravelli, E. Ranzi, C. Candusso, D. Tolazzi, CFD simulation of a turbulent oxy-fuel flame, Process and Technologies for a Sustainable Energy, Ischi June 27-30 2010.

19 M. S. MILLMAN, P. NYSSEN, C. MATHY , D. TOLAZZI, L. LONDERO, C. CANDUSSO, J. C. BAUMERT, M. BRIMMEYER, D. GUALTIERI, D. RIGONI, direct observation of the melting process in an eaf with a closed slag door, ARCHIVES OF METALLURGY AND MATERIALS, Vol. 53, Issue 2, 2008. 